\title{
Vida útil e metabolismo de carboidratos em raízes de mandioquinha-salsa sob refrigeração e filme de PVC
}

\author{
Rosilene Antonio Ribeiro(1), Fernando Luiz Finger(2), Mário Puiatti(2) e Vicente Wagner Dias Casali(2)
}

(1)Faculdade da Amazônia, Instituto do Ensino Superior da Amazônia, CEP 78995-000 Vilhena, RO. E-mail: rosi.ribeiro@hotmail.com (2)Universidade Federal de Viçosa, Dep. de Fitotecnia, CEP 36570-000 Viçosa MG. E-mail: ffinger@ufv.br, mpuiatti@ufv.br, vwcasali@ufv.br

\begin{abstract}
Resumo - O objetivo deste trabalho foi avaliar a influência da temperatura de armazenamento e do uso do filme de cloreto de polivinila (PVC) sobre a perda de matéria fresca e água, incidência de danos causados por frio e metabolismo pós-colheita dos carboidratos, em raízes tuberosas de mandioquinha-salsa (Arracacia xanthorrhiza). $\mathrm{O}$ filme de PVC reduziu a perda de matéria fresca e manteve o teor de água das raízes, durante o armazenamento por 60 dias a 5 e $10^{\circ} \mathrm{C}$. Os danos causados por frio foram inibidos nas raízes embaladas em filme de PCV, em ambas as temperaturas de armazenamento. As baixas temperaturas induziram o acúmulo de açúcares solúveis e a degradação de amido e, para as raízes armazenadas sem PVC, o aumento do conteúdo dos açúcares solúveis foi transiente e a taxa de degradação de amido foi superior à das raízes armazenadas com PVC.
\end{abstract}

Termos para indexação: Arracacia xanthorrhiza, temperatura, atmosfera modificada, teor relativo de água.

\section{Shelf life and carbohydrate metabolism of arracacha roots stored under refrigeration and PVC film}

\begin{abstract}
The objective of this work was to evaluate the influence of the storage temperature and stretch polyvinylchloride (PVC) film on the loss of fresh weight and water, on the development of chilling injury symptoms, and on the postharvest metabolism of carbohydrates, in arracacha tuber roots (Arracacia xanthorrhiza). The PVC film reduced the fresh weight loss and kept water content in the roots during 60-day storage period at 5 and $10^{\circ} \mathrm{C}$. PVC film in both storage temperatures inhibited the development of external and internal chilling injury symptoms. The low temperatures induced the increase of soluble sugar content and decrease of starch concentration, where the increase in soluble sugar was transient in roots stored without PVC film, and the rate of starch degradation was higher compared to the roots stored with PVC.
\end{abstract}

Index terms: Arracacia xanthorrhiza, temperature, modified atmosphere, relative water content.

\section{Introdução}

A mandioquinha-salsa ou batata-baroa é uma hortaliça tuberosa, que se adapta ao cultivo em terras entre 1.500 e $2.500 \mathrm{~m}$ acima do nível do mar, para a qual a temperatura ótima para o crescimento vegetativo é entre $15 \mathrm{e}$ $20^{\circ} \mathrm{C}$ (Santos \& Carmo, 1998). No Brasil, a colheita das raízes dessa planta ocorre entre 10 e 12 meses após o início do cultivo, e uma vez colhidas, as raízes tuberosas se deterioram rapidamente, quando armazenadas em temperatura ambiente.

Henz et al. (2005) observaram que a $24^{\circ} \mathrm{C}$ há perdas de $66 \%$, em quatro dias, nas raízes não lesionadas e de $88 \%$ nas lesionadas mecanicamente. Em estudo recente, verificou-se que as principais causas de perdas pós-colheita de mandioquinha-salsa, no mercado varejista de Viçosa (MG), ocorreram pela incidência de doenças (94\%), seguida da desidratação excessiva $(3,5 \%)$ e, em menor escala, pelos danos mecânicos $(2,5 \%)$ (Marques et al., 2005). Nesse mesmo trabalho, os autores identificaram que a bactéria Erwinia spp. estava presente em $100 \%$ das amostras das raízes com sintomas de apodrecimento.

Como procedimento rotineiro, a diminuição da temperatura de armazenamento é efetiva em reduzir a taxa de deterioração das hortaliças em geral. Porém, para os produtos de origem tropical e subtropical, há necessidade de se adotar temperaturas frias, mas que não estimulem o surgimento de sintomas de danos. Ribeiro et al. (2005), ao avaliar o comportamento pós-colheita de dois clones de mandioquinha-salsa, identificaram a ocorrência de dano por frio, nas raízes dos clones de 'Amarela de Carandaí' 
e 'Roxa de Viçosa', armazenadas a 5 e a $10^{\circ} \mathrm{C}$, porém com menor intensidade na temperatura mais elevada. Os autores observaram sintomas severos a $5^{\circ} \mathrm{C}$, a partir de 14 dias do início do armazenamento, o que inutilizou o produto para comercialização, em razão de escurecimento externo e interno, principalmente na região dos vasos.

A utilização de temperaturas baixas e filmes plásticos pode elevar a conservação pós-colheita da mandioquinha-salsa. Os filmes plásticos favorecem a formação de uma atmosfera modificada, induzida pela respiração do produto, o que reduz o $\mathrm{O}_{2}$ e eleva o $\mathrm{CO}_{2}$ no interior da embalagem, modificações que podem atenuar a severidade do dano causado por frio (Lana \& Finger, 2000). Além disso, as embalagens plásticas são barreiras para o movimento de vapor de água para o ambiente, o que reduz a perda de matéria fresca dos produtos hortícolas (Finger \& Vieira, 1997). Dou (2004) observou que a modificação da atmosfera interna de "grapefruit", induzida pela aplicação de cera à superfície do fruto, reduziu significativamente o desenvolvimento de sintomas de dano por frio, nos frutos armazenados sob temperaturas causadoras do distúrbio. No entanto, em mandioquinha-salsa, o possível efeito da modificação da atmosfera interna da raiz, sobre a redução dos danos causados por frio, não foi ainda avaliada.

$\mathrm{O}$ armazenamento de raízes tuberosas afeta o conteúdo e a composição dos carboidratos, geralmente acompanhados de degradação e interconversão dos carboidratos em consequiência da temperatura, composição atmosférica e infecções pós-colheita. Em cenoura, o armazenamento em baixas temperaturas estimula o acúmulo de hexoses e a redução na concentração de sacarose (Suojala, 2000). Tubérculos de batata, armazenados em temperatura inferiores a $10^{\circ} \mathrm{C}$, são suscetíveis ao processo de adoçamento, pelo aumento da degradação de amido e acúmulo de sacarose e, principalmente, o aumento dos níveis de glicose e frutose (Blenkinsop et al., 2003). Porém, as alterações na composição dos carboidratos não-estruturais, em mandioquinha-salsa, não foram ainda estudadas durante o armazenamento à baixa temperatura e atmosfera modificada.

Este trabalho teve por objetivo avaliar a influência da temperatura de armazenamento e do uso do filme de PVC, sobre a incidência de danos causados por frio e metabolismo dos carboidratos, nas raízes de mandioquinha-salsa.

\section{Material e Métodos}

Raízes tuberosas de mandioquinha-salsa 'Amarela de Carandaí' (BGH 5746) foram colhidas de um campo experimental, da Universidade Federal de Viçosa, MG, provenientes de plantas com dez meses de idade. As raízes sem deformações ou danos foram lavadas, manualmente, com água potável e colocadas em bandejas de poliestireno $(24 \times 18 \times 2 \mathrm{~cm})$, recobertas ou não com filme comercial de PVC (Filmitto, São Paulo). As bandejas, com massa total média de $532 \mathrm{~g}$, foram armazenadas, durante 60 dias, às temperaturas de $5 \mathrm{e}$ $10^{\circ} \mathrm{C}$, com umidade relativa média de $89 \%$ no interior das câmaras.

Foram avaliadas: perda de massa fresca, teor relativo de água, teores de açúcares solúveis totais e de amido, e desenvolvimento de danos causados por frio. A perda de massa das raízes foi determinada pela diferença entre a massa inicial e final do armazenamento, aos 60 dias, expressas em porcentagem.

O teor relativo de água (TRA) foi determinado em discos de $8 \mathrm{~mm}$ de diâmetro e $5 \mathrm{~mm}$ de espessura, retirados do córtex e centro das raízes, conforme Campanha et al. (1997), com a utilização de dez discos por raiz, retirados de três raízes. O TRA foi determinado na colheita aos 15, 30, 45 e 60 dias de armazenamento.

Para a quantificação dos açúcares solúveis totais e amido, amostras das raízes foram maceradas em etanol $80 \%$ a $80^{\circ} \mathrm{C}$, seguida de filtração e duas novas extrações. $\mathrm{O}$ etanol da amostra foi removido em evaporador rotativo a $60^{\circ} \mathrm{C}$, e a fase aquosa foi clarificada pela centrifugação a $12.000 \mathrm{~g}$ por $30 \mathrm{~min}$. Os açúcares solúveis totais foram quantificados pelo método de antrona (Hodge \& Hofreiter, 1962), com utilização de glicose como padrão. A partir do resíduo resultante da extração dos açúcares solúveis, procedeu-se à extração do amido, com ácido perclórico a 40\%, com agitação ocasional por $30 \mathrm{~min}$. Em seguida, centrifugou-se a amostra a $2.000 \mathrm{~g}$ por $10 \mathrm{~min}$. Repetiu-se o mesmo procedimento de extração por três vezes. A quantificação do amido foi feita pelo método de antrona, com utilização de glicose como padrão e multiplicação por 0,9. Em razão do avançado estado de deterioração, a quantificação do conteúdo de açúcares solúveis e de amido das raízes foi realizada: na colheita; aos 15, 30, 45 e 60 dias de armazenamento com PVC; e até os 45, dias para as raízes armazenadas sem filme de PVC.

O desenvolvimento do dano por frio foi avaliado com base em escala arbitrária, desenvolvida previamente por Ribeiro et al. (2005), aos 15, 30, 45 e 60 dias de armazenamento.

O delineamento experimental foi o de blocos ao acaso, com três repetições, com três raízes por repetição. 
Os dados de perda de massa fresca, acumulada ao final do armazenamento, foram submetidos à análise de variância ANOVA, para avaliação da interação temperatura $\mathrm{x}$ tempo de armazenamento $\mathrm{x}$ filme de PVC, e as médias entre tratamentos foram comparadas pelo teste de Tukey, a 5\% de probabilidade. Para a avaliação do efeito dos tratamentos sobre as alterações do teor relativo de água, de teores de carboidratos solúveis totais e de amido, foram determinadas as médias, em intervalos 15 dias, com os respectivos desvios-padrão das médias.

\section{Resultados e Discussão}

No armazenamento a $5^{\circ} \mathrm{C}$, o PVC diminuiu $(\mathrm{p}<0,05)$ a perda de massa das raízes de 58,9 para $8,8 \%$, após 60 dias de armazenamento, enquanto a $10^{\circ} \mathrm{C}$ a redução da perda de massa foi de 31,9 para 3,5\%. Semelhantemente ao observado para raízes de mandioquinha-salsa, os benefícios do uso do filme plástico em reduzir a perda de massa, alterações na firmeza e o desenvolvimento de enrugamento pós-colheita foram documentados em diversos trabalhos com produtos hortícolas (Aharoni et al., 1996; Çelikel et al., 2003).

Nas raízes de mandioquinha-salsa, a perda de firmeza e murcha aparente ocorreram quando a perda de massa acumulada alcançou valores superiores a 9\%. Portanto, aos 60 dias de armazenamento, somente as raízes armazenadas com filme de PVC a 5 e a $10^{\circ} \mathrm{C}$ estavam sem murcha. A perda de massa, após 60 dias de armazenamento, foi maior a 5 do que a $10^{\circ} \mathrm{C}$, independentemente de as raízes estarem embaladas ou não com filme de PVC. Tal fato pode estar relacionado à maior incidência de dano por frio a $5^{\circ} \mathrm{C}$ (Tabela 1 e Figura 1) e a diferenças no gradiente de pressão de vapor entre as raízes e o ar ambiente das câmaras, responsáveis pela desidratação dos tecidos (Kays, 1991).

Tabela 1. Influência da temperatura e do filme de PVC sobre o desenvolvimento de sintomas de deterioração por frio, em raízes de mandioquinha-salsa a 5 e $10^{\circ} \mathrm{C}^{(1)}$.

\begin{tabular}{rccccc}
\hline \multirow{2}{*}{ Dia } & \multicolumn{3}{c}{$5^{\circ} \mathrm{C}$} & & \multicolumn{2}{c}{$10^{\circ} \mathrm{C}$} \\
\cline { 2 - 3 } \cline { 5 - 6 } & Sem PVC & Com PCV & & Sem PVC & Com PCV \\
\hline 0 & 0,0 & 0,0 & & 0,0 & 0,0 \\
15 & 1,9 & 0,0 & & 0,5 & 0,0 \\
30 & 4,0 & 0,0 & & 1,0 & 0,0 \\
45 & 4,0 & 0,0 & & 1,0 & 0,0 \\
60 & 4,0 & 0,0 & & 1,0 & 0,0 \\
\hline
\end{tabular}

(1)Escala de deterioração: 0 , sem deterioração; 1 , levemente deteriorada; 2, moderadamente deteriorada; 3 , severamente deteriorada; 4 , extremamente deteriorada.
O uso do filme de PVC no armazenamento de mandioquinha-salsa inibiu o desenvolvimento de sintomas de deterioração por frio nas raízes, tanto na temperatura de 5 quanto de $10^{\circ} \mathrm{C}$ (Tabela 1 e Figura 1). Sem a proteção do filme de $\mathrm{PVC}$, as raízes apresentaram dano máximo por frio a $5^{\circ} \mathrm{C}$, aos 30 dias de armazenamento, conforme Ribeiro et al. (2005); enquanto no armazenamento a $10^{\circ} \mathrm{C}$, somente sintomas leves de deterioração foram detectados aos 30 dias, tendo permanecido estável até os 60 dias de armazenamento (Tabela 1 e Figura 1).

A aparência externa geral das raízes, durante o armazenamento a 5 e $10^{\circ} \mathrm{C}$, mostra que o filme de PVC reduziu o escurecimento e o aparecimento de deteriorações até os 60 dias de pós-colheita (Figura 1). Nas raízes sem PVC, houve escurecimento e presença de sinais de deterioração aos 15 dias, a $5^{\circ} \mathrm{C}$, e aos 30 dias a $10^{\circ} \mathrm{C}$ (Tabela 1 e Figura 1). Semelhantemente ao observado para a mandioquinha-salsa, o efeito da atmosfera modificada - induzida pela presença do filme de PVC ou por outro tipo de cobertura sobre o produto - em reduzir o aparecimento de sintomas de deterioração por frio, também foi documentada em bananas e "grapefruit" (Dou, 2004; Nguyen et al., 2004).

O filme de PVC reduziu a perda de água, via processo transpiratório, das raízes armazenadas a 5 e a $10^{\circ} \mathrm{C}$. Nas raízes armazenadas sem filme de PVC, houve redução do teor relativo de água de 95,8 para 56,1 e 70,7\%, aos 60 dias a 5 e a $10^{\circ} \mathrm{C}$, respectivamente (Figura 2). Porém, quando armazenadas com filme de PVC, as raízes tiveram menor perda de água e apresentaram teores de 87,3 e $92,4 \%$, a 5 e $10^{\circ} \mathrm{C}$, respectivamente (Figura 2). A perda de água em órgãos de armazenamento é influenciada diretamente pela relação superfície/volume e pelo deficit de pressão de vapor entre o produto e a atmosfera circundante (Finger \& Vieira, 1997); portanto, o filme de PVC reduziu o gradiente de pressão de vapor $\mathrm{e}$, conseqüentemente, diminuiu a perda de água da raiz. $\mathrm{O}$ aumento da umidade no interior da embalagem com PVC contribuiu para a manutenção do nível de turgescência das raízes a 5 e a $10^{\circ} \mathrm{C}$, com redução de apenas 8,5 e 3,4\% de água, respectivamente, em 60 dias de armazenamento (Figura 2). Porém, nas raízes sem filme de PVC, aos 60 dias de armazenamento, houve redução de 39,7 e 25,1\% no conteúdo de água das raízes a 5 e a $10^{\circ} \mathrm{C}$, respectivamente. Cenouras armazenadas sem controle da transpiração por filmes plásticos também apresentam acentuada redução do potencial hídrico das raízes, após dois dias de armazenamento, o que 
indica perda de turgor em razão da desidratação excessiva (Herppich et al., 1999).

Raízes tuberosas armazenadas a 5 e $10^{\circ} \mathrm{C}$, envoltas pelo filme de PCV, apresentaram elevação nos teores de carboidratos solúveis, durante o período de armazenamento de 60 dias, e aumentaram de 3,5\% para valores entre 4,5 e $5 \%$, respectivamente (Figura $3 \mathrm{~A}$ ). Porém, nas raízes armazenadas sem PVC, a elevação $5^{\circ} \mathrm{C}$

Com PVC $\quad 10^{\circ} \mathrm{C}$
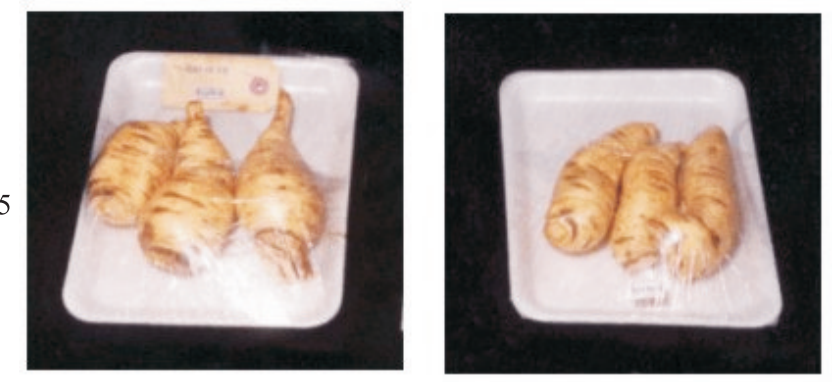

30
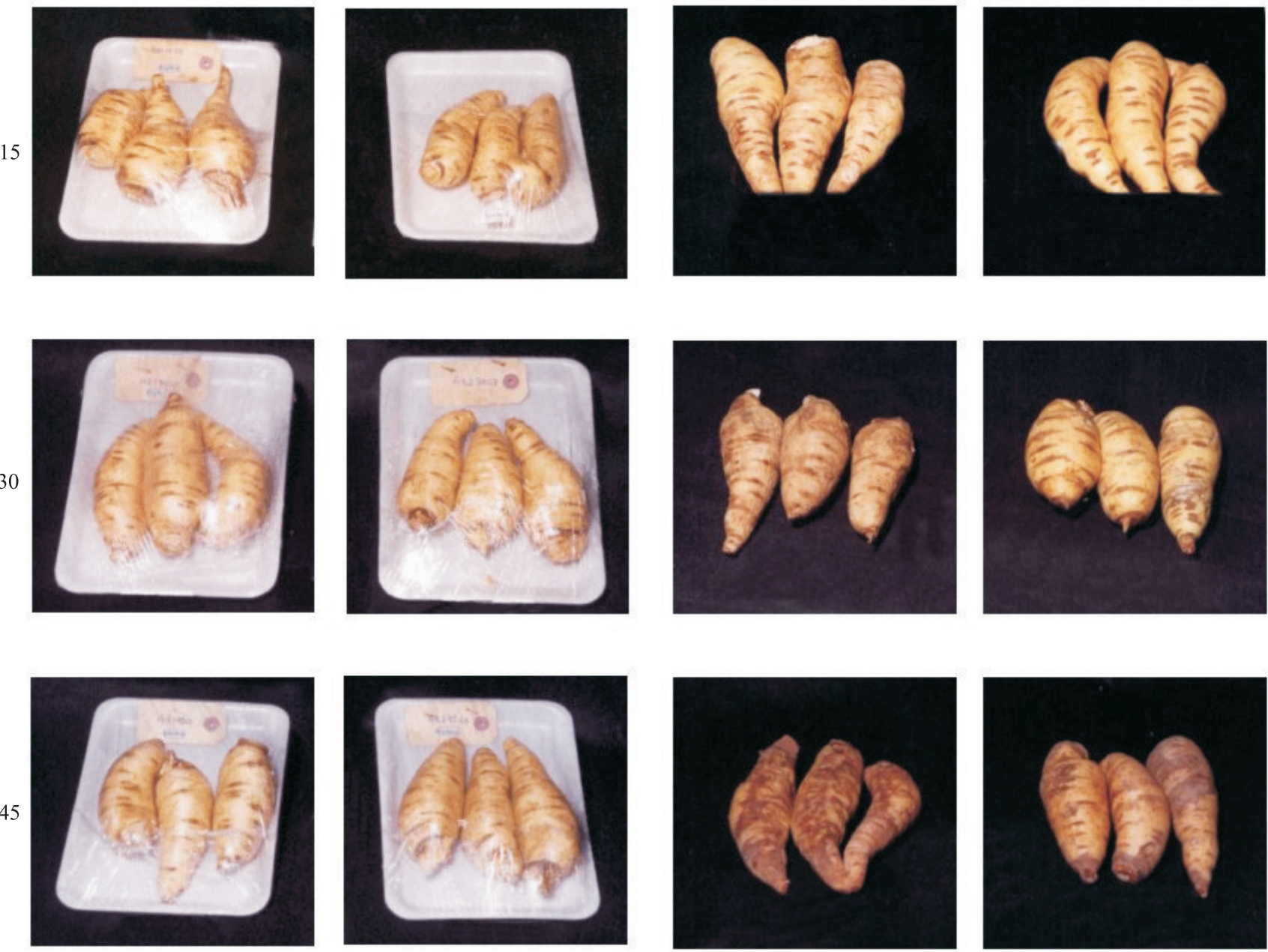

60
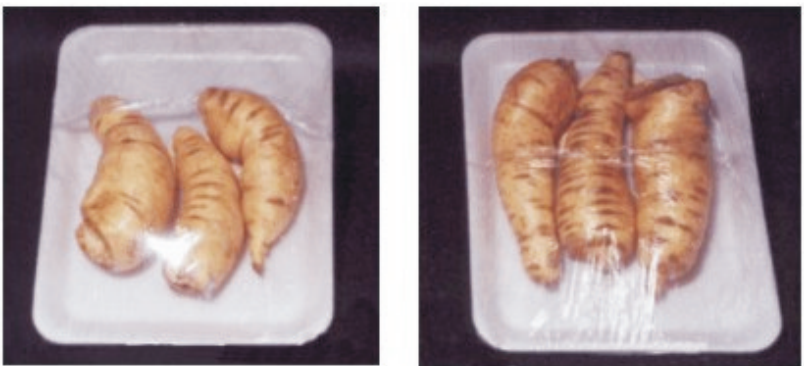

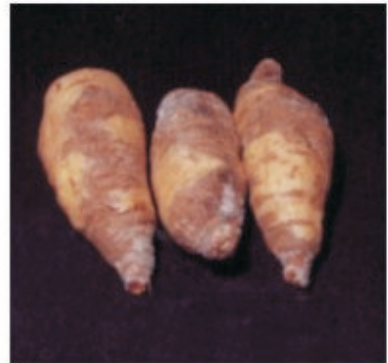

Figura 1. Aparência externa das raízes de mandioquinha-salsa 'Carandaí', armazenadas a 5 e $10^{\circ} \mathrm{C}$ por 60 dias, embaladas ou não com filme de PVC. 
foi transiente e, aos 60 dias de armazenamento, os teores de carboidratos foram semelhantes aos do início da refrigeração. A elevação dos teores dos carboidratos solúveis está relacionada à atividade das enzimas responsáveis pela degradação do amido e pela redução da atividade respiratória, o que resulta em acúmulo desses carboidratos. Este comportamento também ocorre em batata, em que o armazenamento em condições de baixa temperatura $\left(4-6^{\circ} \mathrm{C}\right)$ estimula o acúmulo de açúcares solúveis, principalmente glicose, frutose e sacarose, o que leva ao adoçamento (Kumar et al., 2004).

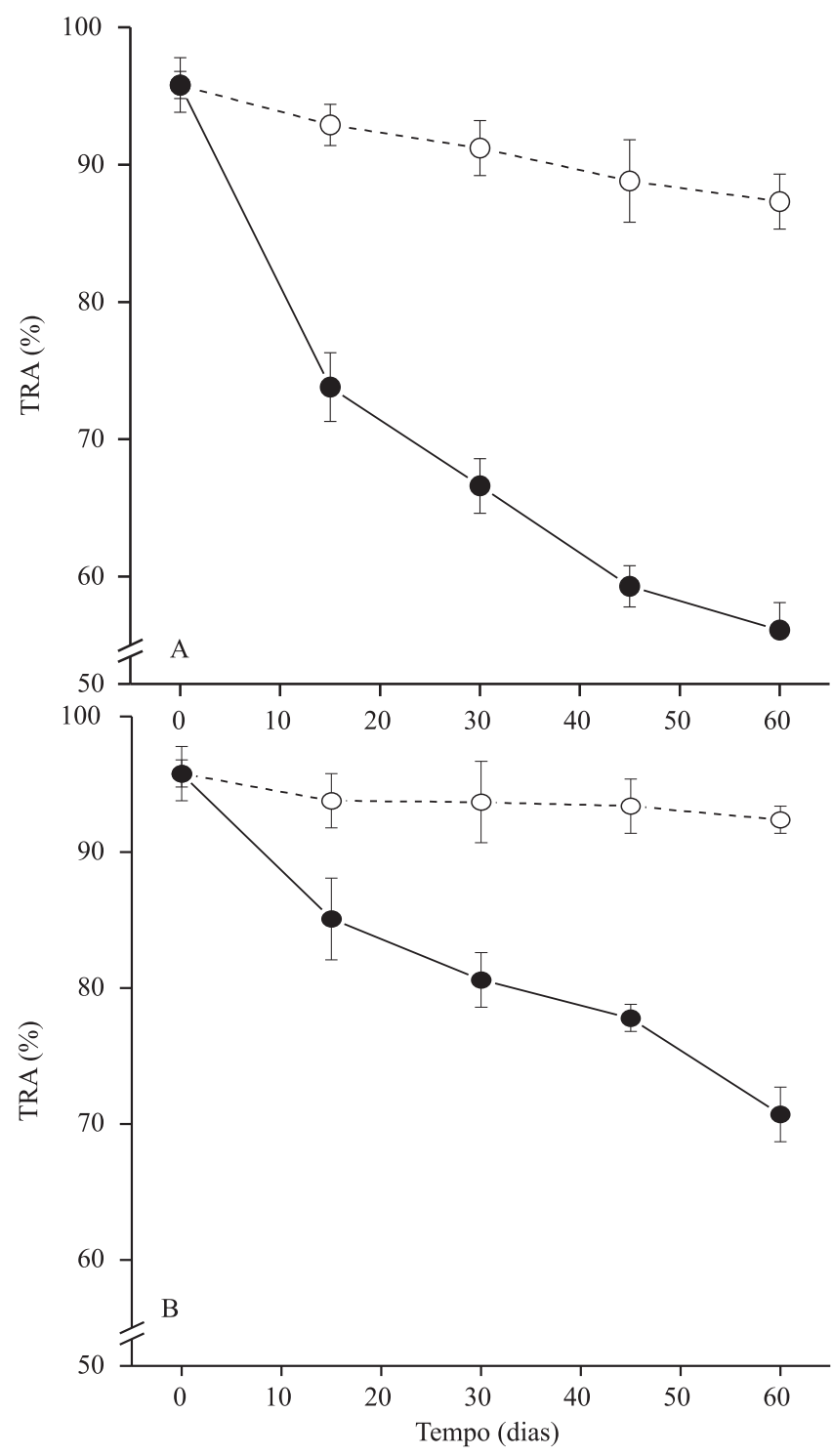

Figura 2. Teor relativo de água (TRA) em raízes de mandioquinha-salsa armazenadas a $5^{\circ} \mathrm{C}(\mathrm{A})$ e a $10^{\circ} \mathrm{C}(\mathrm{B})$, embaladas com filme de PVC (O) e sem filme de PVC (•). As barras verticais representam o desvio-padrão da média.
Os teores de amido das raízes, armazenadas sem filme de PVC, foram reduzidos de 18,5 para cerca $12,5 \%$, ao final dos 60 dias de armazenamento a 5 e a $10^{\circ} \mathrm{C}$ (Figura $3 \mathrm{~B}$ ), enquanto os teores de carboidratos solúveis praticamente não sofreram alteração (Figura $3 \mathrm{~A}$ ). Nas raízes envoltas pelo PVC, os teores de amido, ao final do armazenamento, foram 16,4 e 16,6\%, respectivamente (Figura 3 B), com elevação dos teores de carboidratos solúveis (Figura 3 A). Isto, provavelmente, ocorreu em

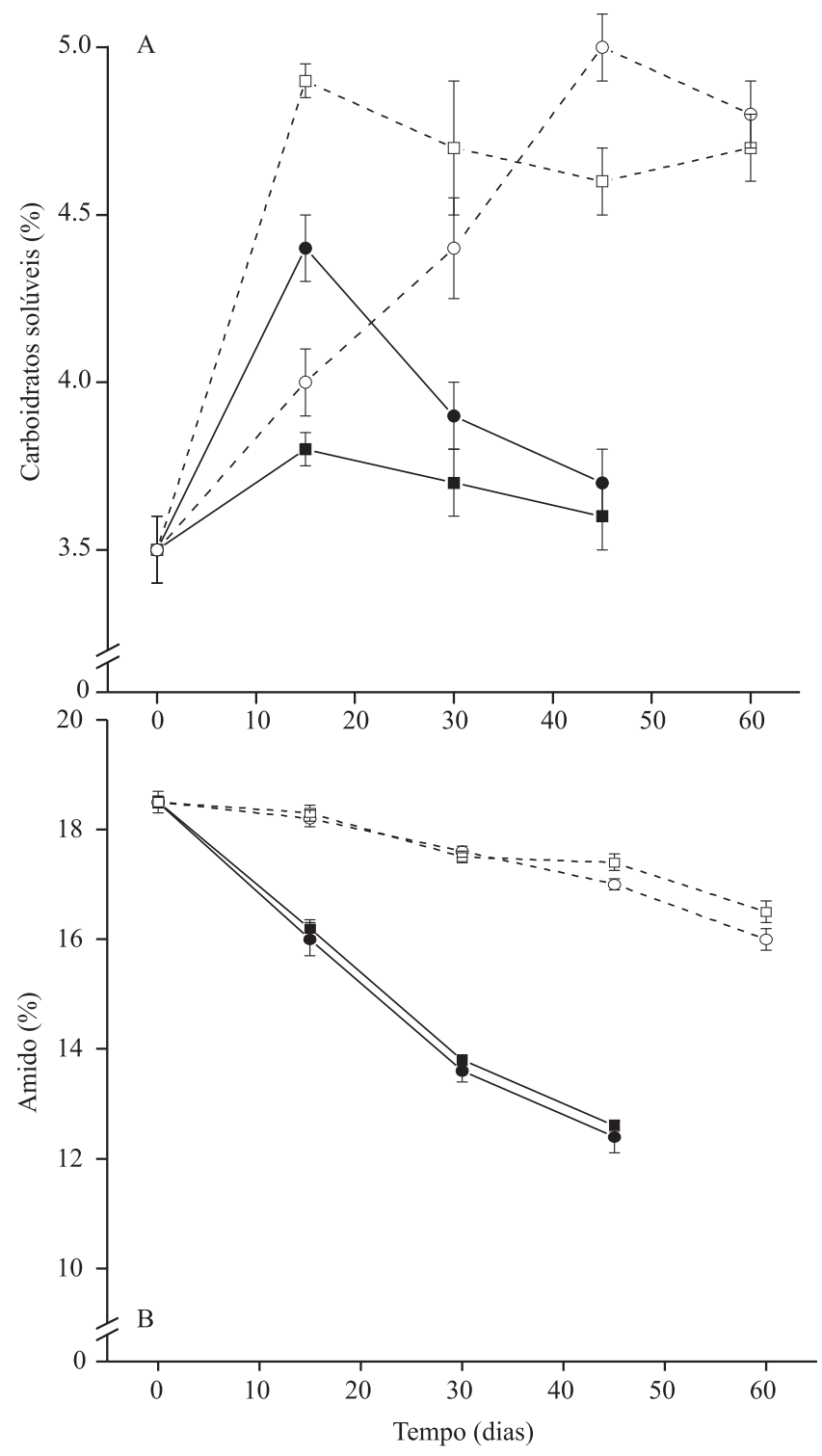

Figura 3. Teor de açúcares solúveis (A) e de amido (B), em raízes de mandioquinha-salsa, armazenadas a $5^{\circ} \mathrm{C}(\mathrm{O})$ e a $10^{\circ} \mathrm{C}(\bullet)$ com filme de PVC, e a $5^{\circ} \mathrm{C}(\square)$ e a $10^{\circ} \mathrm{C}(\boldsymbol{\square})$ sem filme de PVC. As barras verticais representam o desvio-padrão da média. 
razão da menor taxa respiratória das raízes e do estresse oxidativo decorrente da formação de atmosfera modificada no interior da embalagem (Lana \& Finger, 2000; Toivonen, 2003).

\section{Conclusões}

1. O filme de PVC reduz a perda de matéria fresca, mantém o teor relativo de água e minimiza a degradação do amido, em raízes de mandioquinha-salsa armazenadas a 5 e $10^{\circ} \mathrm{C}$ por 60 dias.

2. Não há desenvolvimento de danos visíveis causados por frio, nas raízes armazenadas por 60 dias, embaladas com filme de PVC.

3. $\mathrm{O}$ armazenamento às temperaturas de 5 e $10^{\circ} \mathrm{C}$ induz ao acúmulo de açúcares solúveis e à intensa degradação do amido.

\section{Agradecimentos}

À Capes, pela concessão da bolsa de estudos à Rosilene Antonio Ribeiro.

\section{Referências}

AHARONI, Y.; COPEL, A.; GIL, M.; FALLIK, E. Polyolefin stretch films maintain the quality of sweet corn during storage and shelf-life. Postharvest Biology and Technology, v.7, p.171-176, 1996.

BLENKINSOP, R.W.; COPP, L.J.; YADA, R.Y.; MARANGONI, A.G. A proposed role for the anaerobic pathway during low-temperature sweetening in tubers of Solanum tuberosum. Physiologia Plantarum, v.118, p.206-212, 2003.

CAMPANHA, M.M.; FINGER, F.L.; CECON, P.R.; BARBOSA, J.G. Water relations of cut bird-of-paradise (Strelitzia reginae Ait.) inflorescences. Revista Brasileira de Horticultura Ornamental, v.3, p.27-31, 1997.

ÇELIKEL, F.G.; KAYNAS, K.; ERENOGLU, B. A study on modified atmosphere storage of strawberry. Acta Horticulturae, v.628, p.423-430, 2003.

DOU, H. Effect of coating application on chilling injury of grapefruit cultivars. HortScience, v.39, p.558-561, 2004.
FINGER, F.L.; VIEIRA, G. Controle da perda pós-colheita de água em produtos hortícolas. Viçosa: UFV, 1997. 29p. (Cadernos didáticos, 19).

HENZ, G.P.; SOUZA, R.M.; PEIXOTO, J.R.; BLUMER, L. Danos causados pelo impacto de queda na qualidade pós-colheita de raízes de mandioquinha-salsa. Horticultura Brasileira, v.23, p.881-886, 2005.

HERPPICH, W.B.; MEMPEL, H.; GEYER, M. Effects of postharvest mechanical and climatic stress on carrot tissue water relations. Postharvest Biology and Technology, v.16, p.43-49, 1999.

HODGE, J.E.; HOFREITER, B.R. Determination of reducing sugars and carbohydrates. In: WILSTER, R.L.; WOLFROM, M.L. (Ed.). Methods in carbohydrate chemistry. New York: Academic Press, 1962. v.1, p.380-394.

KAYS, S.J. Postharvest physiology of perishable plant products. New York: Van Nostrand Reinhold, 1991. 532p.

KUMAR, D.; SINGH, B.P.; KUMAR, P. An overview of the factors affecting sugar content of potatoes. Annals of Applied Biology, v.145, p.247-256, 2004.

LANA, M.M.; FINGER, F.L. Atmosfera modificada e controlada: aplicação na conservação de produtos hortícolas. Brasília: Embrapa Comunicação para Transferência de Tecnologia: Embrapa Hortaliças, 2000. 34p.

MARQUES, L. de C.S.; FINGER, F.L.; MENDONÇA, H.L. de; SOUZA, S.O. de. Perdas de mandioquinha-salsa, durante a comercialização, na rede varejista de Viçosa-MG. Horticultura Brasileira, v.23, p.439, 2005. Suplemento.

NGUYEN, T.B.T.; KETSA, S.; DOORN, W.G. van. Effect of modified atmosphere packaging on chilling-induced peel browning in banana. Postharvest Biology and Technology, v.31, p.313-317, 2004.

RIBEIRO, R.A.; FINGER, F.L.; PUIATTI, M.; CASALI, V.W.D. Chilling injury sensitivity in arracacha (Arracacia xanthorrhiza) roots. Tropical Science, v.45, p.55-57, 2005.

SANTOS, F.F.; CARMO, C.A.S. Mandioquinha-salsa: manejo cultural. Brasília: Embrapa-SPI: Embrapa-CNPH, 1998. 79p.

SUOJALA, T. Variation in sugar content and composition of carrot storage roots at harvest and during storage. Scientia Horticulturae, v.85, p.1-19, 2000.

TOIVONEN, P.M.A. Effects of storage conditions and postharvest procedures on oxidative stress in fruits and vegetables. In: HODGES, D.M. (Ed.). Postharvest oxidative stress in horticultural crops. New York: Food Products Press, 2003. p.69-90. 